\title{
TRAYECTORIAS Y ACTITUDES GENERACIONALES Temporalidades y actitudes ante la educación, el trabajo y el consumo de tres generaciones de jóvenes españoles y portugueses
}

\author{
José Durán Vázquez \\ Universidad de Vigo, Vigo, España
}

Eduardo Duque

Universidade Católica Portuguesa, Braga, y CECS, Universidade do Minho, Braga, Portugal

Resumen Este trabajo se propone analizar las trayectorias biográficas de tres generaciones de jóvenes españoles y portugueses (1935-1945, 1955-1965 y 1975-1985) en relación con sus actitudes hacia el mundo de la educación, el trabajo y el consumo. Para la realización de esta investigación, se han empleado como fuentes los distintos Informes de Juventud publicados regularmente desde 1960. Los resultados obtenidos permiten llegar a las siguientes conclusiones: la generación de 1935-45, ha sido la más influenciada por la ética del trabajo; la de 1955-1965 es la primera que participa de los valores de los tres ámbitos analizados; la juventud del periodo 1975-85, es la más socializada en los valores del consumo, valores que ejercerán una mayor influencia sobre los otros dos ámbitos, el educativo y el laboral.

Palabras-clave: juventud, valores, generaciones.

Resumo Este trabalho tem como objetivo analisar as trajetórias biográficas de três gerações de jovens espanhóis e portugueses (1935-1945, 1955-1965 e 1975-1985) em relação às suas atitudes perante o mundo da educação, do trabalho e do consumo. Para a concretização desta investigação, recorreu-se aos diferentes Relatórios da Juventude, publicados regularmente desde 1960. Os resultados obtidos permitem chegar às seguintes conclusões: a geração de 1935-45 foi a mais influenciada pela ética do trabalho; a de 1955-65 é a primeira que participa dos valores dos três âmbitos analisados; a juventude do período 1975-85 é a geração mais socializada nos valores do consumo, valores que exercerão maior influência nos outros dois âmbitos, no educativo e laboral.

Palavras-chave: juventude, valores, gerações.

Abstract The objective of this study was to analyse the biographic trajectories of three generations of young Spaniards and Portuguese (1935-1945, 1955-1965, 1975-1985) in terms of their attitudes towards the world of education, work and consumption. The researchers used various Relatórios da Juventude (Youth Reports), which have regularly been published since 1960 . The results permit a number of conclusions: the 1935-45 generation was the most heavily influenced by the work ethic; the 1955-65 generation was the first to share certain values regarding all three areas; those who were teenagers in 1975-85 are the generation that is the most highly socialised in terms of consumer values, which are in turn likely to have a greater influence on the educational and work-related fields.

Keywords: youth, values, generations.

Résumé Cet article analyse les trajectoires biographiques de trois générations de jeunes espagnols et portugais (1935-1945, 1955-1965 et 1975-1985) en ce qui concerne leurs attitudes face au monde de l'éducation, du travail et de la consommation. Cette recherche s'appuie sur les différents “ Rapports de la Jeunesse ” publiés régulièrement depuis 1960. Les résultats obtenus permettent de tirer les conclusions suivantes : la génération de 1935-45 a été davantage influencée par l'éthique du travail ; celle de 1955-65 est la première qui partage les valeurs des trois domaines analysés ; la jeunesse de la période 1975-85 est la génération la plus socialisée dans les valeurs de la consommation, c'est-à-dire celles qui exercent la plus forte influence sur les deux autres domaines, à savoir l'éducation et le travail.

Mots-clés: jeunesse, valeurs, générations. 


\section{Introducción}

El objetivo del texto que a continuación presentamos es analizar los valores y las actitudes ante el trabajo, la educación y el consumo, así como las concepciones del tiempo de tres generaciones de jóvenes españoles y portugueses en el contexto del proceso de transición de una sociedad rural y preindustrial a otra urbana e industrial, y de esta a la postindustrial.

Planteamos la hipótesis de que la juventud de ambos países habría experimentado durante este periodo un importante cambio en relación con su integración y su actitud hacia dichos ámbitos. Así, en un primer momento, durante la etapa urbana-industrial, los valores del trabajo y de la educación serían los dominantes, confiriendo una determinada identidad a la juventud de esta época. Más tarde, a medida que se va transitando hacia la etapa postindustrial, los valores del consumo irán cobrando una mayor fuerza con respecto a los valores educativos y los laborales. En este contexto, la educación y el trabajo adquirirán un carácter más instrumental para la mayoría de los jóvenes, en función de la lógica imperante en el mundo del consumo. Produciéndose, además, una progresiva separación entre los espacios y los tiempos dominantes en cada uno de estos ámbitos.

Para poner a prueba dicha hipótesis hemos seleccionado tres generaciones de jóvenes españoles y portugueses (1935/1945; 1955/1965; 1975/1985), que coinciden con las etapas que anteriormente hemos señalado.

\section{Objetivos, cuestiones teóricas y metodológicas}

Antes de adentrarnos en la exposición más detallada de lo que será el objetivo del presente trabajo, consideramos preciso aclarar, aunque sólo sea brevemente, algunos de los conceptos centrales que lo articulan.

Desde una perspectiva más elemental pueden considerarse jóvenes todas aquellas personas que han abandonado la infancia sin haber entrado todavía en la edad adulta. No obstante, esta diferenciación es poco clarificadora, toda vez que cada sociedad tiene su propia manera de entender esta etapa de la vida (Becci y Julia, 1998; Lévi y Schmitt, 1996).

Desde este punto de vista, en las tres generaciones que se analizarán seguidamente la duración de la juventud estará determinada por la más temprana o tardía incorporación a los ámbitos institucionales característicos del mundo adulto. Y la identidad juvenil vendrá conformada a partir de las experiencias sociales que constituyen el marco de la historia compartida por los miembros de cada generación (Margulis y Urresti, 1996: 26). Estas experiencias se construirán, en el caso de las tres generaciones que hemos diferenciado en este estudio, a partir de la diferente integración de los miembros de cada generación en el mundo del trabajo, la educación y el consumo, configurando así una determinada memoria, y también una serie de valores y de expectativas.

En este contexto cobra precisamente sentido el concepto de generación (Mannheim, 1990). En efecto, la generación es más que una coincidencia cronológica 
(Martín Serrano, 1994: 18; Leccardi y Feixa, 2011:17 y ss.), puesto que conlleva una serie de experiencias, actitudes y valores comunes en relación con diversos ámbitos sociales y culturales. Experiencias y actitudes que serán más o menos fuertes en virtud de su capacidad para articular la vida social e individual de los miembros de cada generación.

Precisemos una importante cuestión más, no por ello menos importante. La juventud no puede ser percibida únicamente como una categoría de edad, en ella influyen otras variables que también intervienen en su configuración, como por ejemplo la clase social (Martín Criado, 1998: 67 y ss.). La cuestión que en este caso se plantea es si estas variables ejercen tanta influencia que no tendría sentido referirse a la juventud como una experiencia socio-cultural común.

Sin negar la diversidad de circunstancias que configuran la condición de ser joven, creemos que es posible observar ciertas actitudes y experiencias comunes relativas a la juventud de cada periodo que es posible analizar, explicar y comprender en términos generacionales (Elzo, 1999: 404-405).

Con este criterio hemos diferenciado tres generaciones. La primera se correspondería con los nacidos en el periodo 1935/1945, socializados fundamentalmente en la ética del trabajo.

La segunda generación - la del periodo 1955/1965 - pertenece a un momento de transición, en el que los valores del consumo van cobrando un mayor protagonismo con respecto a los del trabajo y a los educativos, de tal forma que estos últimos comienzan a ser mediados por aquellos.

Por último, la tercera generación - la de los nacidos entre 1975/1985 - es la conformada por los jóvenes que se definen ante todo como consumidores. Se trata, por ello, de la generación más plenamente socializada en los valores del consumo, que van a ejercer una mayor influencia sobre el ámbito educativo y el laboral, contribuyendo a transformar las expectativas de los jóvenes hacia cada uno de estos ámbitos, que finalmente resultarán atravesados por los valores del consumo.

Desde el punto de vista metodológico, se han empleado para realizar el presente estudio diferentes informes y encuestas pertenecientes al periodo cronológico que abarcan las tres generaciones objeto de nuestro análisis.

En el caso de España se han analizado fundamentalmente los distintos Informes de Juventud publicados periódicamente desde 1960 bajo el patrocinio de diferentes instituciones, que proporcionan un completo cuadro temporal de la evolución de los valores y actitudes de este grupo de edad (De Miguel, 2000: 15).

Para Portugal se ha recurrido a diversos estudios realizados en el ámbito del Observatório Permanente da Juventude, creado por la Secretaria de Estado da Juventude, que hasta la fecha ha producido diversos trabajos sobre la realidad de la juventud portuguesa. Se han utilizado, asimismo, los datos oficiales del Instituto Nacional de Estatística, del Ministério da Educação, del Instituto do Emprego e Formação Profissional, y del Ministério do Trabalho e da Solidariedade. No existe sin embargo en este país un cuadro longitudinal tan completo de encuestas de juventud, como el que sí hay en España. Si bien se cuenta con un pionero y muy completo estudio sobre la juventud universitaria portuguesa (Nunes, 1968), dicho estudio no tuvo la regularidad deseable en el tiempo, de modo que hasta los años 
80 no comienzan a proliferar los análisis sociológicos sobre la juventud portuguesa (Guerreiro y Abrantes, 2003: 241). Además, muchos de estos trabajos, sobre todo los producidos hasta los años 90 , se basan más en fuentes estadísticas que en encuestas de opinión. Por todas estas razones, las comparaciones entre ambos países resultan en ocasiones difíciles y complejas, por lo que en el caso particular de las dos primeras generaciones no hemos podido llevarlas al ámbito de las vivencias y de las representaciones del tiempo. De todos modos, aun con todas estas limitaciones, hemos intentado, y esperamos haberlo logrado en alguna medida, hacer una primera aproximación a la comparación entre las juventudes de ambos países. El resultado es el que mostraremos seguidamente.

\section{Generaciones}

Generación 1935-1945

Es la generación menos identificada con una hipotética cultura juvenil o adolescente, ya que en el periodo de su juventud el modelo social a imitar era todavía el de los adultos, representados sobre todo por la figura del padre. En este rol paterno se reconocen todavía muchos de ellos, y por tanto también en las estructuras de una familia jerárquica con fuertes divisiones de género. Así aparece al menos reflejado en la encuesta de Juventud de 1960 (De Lora, 1965: 63 y ss., 119 y ss.).

¿Cuál es la orientación de los miembros de esta generación hacia cada uno de los ámbitos analizados en el presente texto?

\section{Educación}

En el caso de España, la generación de los nacidos entre 1935 y 1945 es la que tiene una más baja participación académica, tanto en estudios secundarios como universitarios. En el año 1960 únicamente estudiaban el $25 \%$ de los jóvenes comprendidos entre 15 y 20 años, con un importante componente de clase (De Lora, 1965: 57-58; Beltran, 1984: 24). Todavía en 1970 únicamente el $8 \%$ de los estudiantes universitarios eran hijos de obreros (De Miguel, 2000: 44 y ss.).

No obstante, y a pesar de su escasa participación educativa, la educación era percibida por los hijos de los obreros como un mecanismo de movilidad social, en relación con las posibilidades que parecía ofrecer el medio industrial, pero también por el prestigio que se atribuía a la posesión de un determinado nivel cultural (De Miguel, 2000: 64; De Lora, 1965: 174).

En Portugal, la participación académica de la juventud de esta generación era todavía más baja que la de España (en 1960 la tasa de escolarización - nos referimos a los que frecuentaban la enseñanza superior - de los jóvenes comprendidos entre 15 y 29 años era apenas del 6,6\% (INE, 1960).

Se trata de un momento - en los años 60 - en el que el país todavía no había abordado las grandes reformas de la enseñanza, emprendidas más tarde por Veiga Simão, y consolidadas después del 25 de Abril. La enseñanza tenía, pues, tanto en 
Portugal como en España, un fuerte componente de clase, especialmente en el caso de la universidad, en la que la gran masa de los estudiantes - entre el $76 \%$ y el $90 \%$ - procedía de los dos grupos que detentaban las posiciones socioeconómicas más favorecidas (Nunes, 1968: 327).

Trabajo

Los valores del trabajo eran relativamente sólidos para los jóvenes españoles de esta generación. En realidad, para muchos de ellos no existían otros valores que compitiesen eficazmente con los laborales, pues el trabajo era la ocupación principal de la mayoría de esta juventud (De Miguel, 2000: 141). Así, entre las cualidades que más dicen admirar de sus padres los jóvenes de 1960, con independencia de su clase social, ${ }^{1}$ estaban el "ser trabajador" y el tener "sentido del negocio" (De Lora, 1965: 59-60). El trabajo como ideal de vida conformaba de este modo la mentalidad de la mayoría de los jóvenes, no sólo por razones de orden material - las del salario - sino también por lo que significaba en términos de cumplimiento del deber personal, social y moral (Muñoz Carrión, 1994: 216).

En Portugal, esta etapa generacional coincide, al igual que había ocurrido en España, con un periodo de importante desarrollo económico, que no alcanzó sin embargo la dimensión que tuvo en el vecino país ibérico. Así, de una tasa de crecimiento que rondaba el 3,5\% entre 1956-1958, se pasó a otra del 5,3\% en 1959, y de esta al 8,8\% en 1960 (OECD). Es el momento, por tanto, en el que Portugal comienza a industrializarse al compás de este impulso económico (Rocha: 1977: 595).

\section{Consumo}

Mientras que los valores del trabajo tenían una fuerte ascendencia para los jóvenes españoles de esta generación, los del consumo apenas estaban presentes. La moda, que será una de las principales manifestaciones de dicha cultura en los jóvenes de las generaciones posteriores, apenas era valorada por la mayoría de los miembros de esta generación, al menos a tenor del escaso repertorio de su vestuario (Alonso y Conde, 1994: 155; De Miguel, 2000: 36). En cuanto al ocio, otro de los aspectos que posteriormente más se vinculará con el estilo de vida juvenil, no aparece entre las dimensiones que los jóvenes consideran que van a ser más importantes en sus experiencias futuras - en 1960, únicamente el $8 \%$ de los estudiantes, que son los que disponen de más tiempo libre, valoraba el ocio como una actividad importante en el futuro (De Miguel, 2000: 63-64). Aun así, en contraste con sus padres, comenzaban a apreciar el entretenimiento y la diversión como ámbitos a tener en cuenta también en la vida (De Lora, 1965: 65), y por ello reclaman también una mayor libertad, aunque se trate más de una libertad de hacer que de pensar (Velarde, 1994: 107).

1 En la encuesta de 1960 se dividió a los jóvenes en tres grupos: estudiantes, campesinos y trabajadores (De Lora, 1965). 
En Portugal, aunque no se dispone para este periodo de encuestas de juventud que interroguen a los jóvenes específicamente sobre su consumo, podemos decir que la juventud portuguesa iba alimentando los sueños de abandonar la vida dura del mundo agrario tradicional, cuyo espejo eran sus progenitores.

A semejanza de lo que ocurría en España, las preocupaciones de la juventud portuguesa de esta generación giraban más alrededor de la familia y del trabajo que del tiempo de ocio y de consumo (Pais, 1996: 199).

\section{Tiempo}

La concepción del tiempo de los jóvenes españoles de esta generación se vinculaba a su deseo de superar el pasado de la sociedad agraria y preindustrial para integrarse en el futuro del mundo urbano e industrial. En otras palabras, los sacrificios del presente estaban orientados a la superación del pasado, pensando en una mejor vida futura, de acuerdo con una cierta idea de la gratificación postergada. Por eso la mayoría de ellos (el 63\%) estaba en desacuerdo con la pregunta que les planteaba la encuesta del CIS de 1967, a saber "el futuro es tan inseguro para los jóvenes que mejor es vivir al día" (De Miguel, 2000: 258; Muñoz Carrión, 1994: 213-214). Más de la mitad de los jóvenes encuestados en 1968 (el 52\%), creían, por el contrario, que les aguardaba un futuro prometedor, siendo muy pocos (el 16\%) los que lo enfrentaban con una actitud pesimista (Muñoz Carrión, 1994: 207-208).

Muchas de las actitudes y de los valores presentes en los miembros de esta generación van a experimentar importantes cambios en los jóvenes de la siguiente generación. Cambios, que como veremos, emergerán gradualmente, haciéndose más visibles en los nacidos iniciada ya la década de los 60 .

Tabla 1 Generación 1935-1945

\begin{tabular}{lll}
\hline & Valores & Actitudes \\
\hline Educación & $\begin{array}{l}\text { Fuertes, promoción social y } \\
\text { cultural. }\end{array}$ & $\begin{array}{l}\text { Progreso material y social. } \\
\text { Reproducción social. } \\
\text { Orientadas claramente a la integración. }\end{array}$ \\
\hline Trabajo & $\begin{array}{l}\text { Fuertes, asociados a un deber } \\
\text { material, social y moral. }\end{array}$ & $\begin{array}{l}\text { Progreso personal y social. } \\
\text { Reproducción social. } \\
\text { Favorables a la integración. }\end{array}$ \\
\hline Consumo & Débiles, supeditados al trabajo. & $\begin{array}{l}\text { Divertirse para recuperarse del cansancio } \\
\text { laboral. } \\
\text { Liberarse un poco del tiempo productivo. }\end{array}$ \\
\hline Tiempo & & Superar el pasado y progresar en el futuro. \\
\hline
\end{tabular}




\section{Generación 1955-1965}

Es la primera generación, particularmente la de los jóvenes nacidos en los años 60, que integra los mundos de la educación, del trabajo y del consumo, coincidiendo con la fase de transición entre la sociedad industrial y la postindustrial.

\section{Educación}

En el caso de España, será la generación que protagonizará - especialmente los nacidos en la década de los 60 - la expansión educativa en sus distintos niveles. ${ }^{2}$ No obstante, al coincidir dicha expansión con una etapa de crisis económica, se observa también un progresivo descenso de las expectativas con respecto a los estudios - en 1975 el 21\% tenía confianza en que los estudios le sirviesen para tener éxito en la vida; sin embargo en 1982 esta cifra había descendido al 10\% (Martín Escudero, 1994: 130-131). Aun así, seguían siendo mayoría - más de la mitad - los que albergaban la esperanza de que sus títulos les ayudasen a conseguir un trabajo satisfactorio, tal como se mostraba en las encuestas realizadas entre 1974 y 1984 (Martín Escudero, 1994: 146; Beltrán, 1984: 65 y ss.). No obstante, existían ciertas diferencias entre las distintas clases sociales. Así, mientras que los miembros de las clases altas y medias-altas valoraban los estudios como instrumento del éxito profesional, las clases obreras urbanas pretendían, por el contario, comenzar pronto a trabajar para integrarse en los escenarios del mundo adulto. Finalmente, los hijos de las clases medias-bajas urbanas compartían ambas actitudes (Beltrán, 1984: 200-201).

En Portugal esta generación coincide también con una fuerte expansión educativa, la de los años 70. La educación será valorada principalmente por la mayoría de los jóvenes en relación con el mercado de trabajo. Así, según la encuesta de la FAOJ (Fundo de Apoio aos Organismos Juvenis) de 1982 el 70\% de los jóvenes consideraban que la escuela tenía como principal objetivo ayudar a conseguir una profesión. En esta misma línea se situaba la encuesta de la IED de 1983 (Ferreira, 1993). De todos modos, se apreciaban importantes diferencias de clase. Así, los jóvenes de familias de clases medias y altas percibían la educación de acuerdo con estrategias de promoción o de reproducción social (Schmidt, 1990). Mientras que los de los estratos sociales más desfavorecidos invocaban razones de orden económico para abandonar tempranamente la escuela (Schmidt, 1990).

De este modo, tanto en Portugal como en España, mientras que los jóvenes de clases medias y superiores manifiestan una orientación hacia los estudios basada en la movilidad y la reproducción social, los de clases más bajas abandonan tempranamente la educación buscando los medios materiales que no les proporciona el medio escolar.

2 Mientras que en 1960 sólo el 25\% de los jóvenes menores de 21 años estaba estudiando, a mediados de los 80 esta cifra se había elevado al 60\%, y en el 1991 era ya del 64\% (Beltrán, 1984: 55; De Miguel, 1992: 593). 
Trabajo

¿Qué ocurre con los valores del trabajo? En España se advierte también una transición, sobre todo a partir de los años 80, momento en el que se acentúa el descenso de la tasa de actividad juvenil (19\% en 1982 para la población comprendida entre 15 y 20 años). Proceso que corre paralelo al incremento constante de la población escolar (Beltrán, 1984: 25 y ss.).

De este modo, a partir sobre todo de mediados de los años 80, el trabajo comienza a perder centralidad, valorándose cada vez menos de esta actividad todos aquellos aspectos vinculados con su dimensión social y moral (Andrés Orizo, 1989: 196; 1995: 99; De Miguel, 1992: 589-590; González Blasco, 1994: 41). Y cada vez más otras dimensiones más instrumentales, tales como los ingresos, la sociabilidad y la seguridad (Andrés Orizo, 1983: 262-265). Que ya eran las más apreciadas por los jóvenes de 18 a 24 años en las encuestas del periodo 1981-1994, por encima de otras como la utilidad social o el logro (Andrés Orizo, 2001: 232-233; Martín Escudero, 1994: 162). Todo ello ponía de manifiesto la progresiva erosión de los valores del trabajo entre la juventud (Andrés Orizo, 1989: 196).

Para los jóvenes portugueses de esta generación el trabajo se percibía como una forma de realización personal y profesional, y no como una actividad instrumental, tal como comenzaba a ocurrir con los jóvenes españoles a partir de los años 80 - únicamente el 6,2\% consideraba en 1987 que era importante tener un trabajo "para obtener el dinero que se precisa para satisfacer necesidades de consumo" (Ferreira, 1993). Eran muchos más - según la encuesta del ICS (Instituto de Ciências Sociais) de 1987 - los que valoraban la realización profesional como el aspecto más importante de su vida futura (50\%), o como una dimensión muy importante de ella (82\%). Asimismo, según la misma encuesta, el 71,2\% de los jóvenes consideraban importante "tener un trabajo que les gustase realizar" (Ferreira, 1993).

\section{Consumo}

Mientras que los valores y las actitudes asociados a la actividad laboral comenzaban a adquirir un carácter más instrumental a partir de comienzos de la década de los años 80 en la juventud española, los valores del consumo se consolidarán cada vez más a partir de esta fecha. Así, en 1981 eran mayoría los jóvenes de 18 a 20 años y de 20 a 24 - el $63 \%$ de los primeros y el $57 \%$ de los segundos - que lamentaba con pesar que acabase el fin de semana para volver de nuevo al trabajo (Andrés Orizo, 1983: 286).

Estos datos mostraban que se estaba produciendo un cambio de actitudes en una juventud que se orientaba cada vez más hacia los valores hedonistas y de autoexpresión personal, vinculados a un mayor deseo de vivir el presente a costa de la renuncia a los valores de la gratificación postergada.

En Portugal, comienza también a advertirse una mayor identificación de los jóvenes con los valores del consumo. Aunque este proceso comienza un poco más tarde que en España, aproximadamente en torno a finales de la década de 
los 80. Así lo ponía de manifiesto la encuesta del ICS de 1987, en la que la mayoría de los jóvenes, con independencia de su clase social, manifestaba un parecido interés por los bienes vinculados a los audiovisuales y a las nuevas tecnologías, aunque, claro está, eran los miembros de las clases sociales más favorecidas los que más convertían sus sueños en realidad (Andrade, 1989). De todos modos, se estaba instalando gradualmente en la juventud portuguesa una mentalidad cada vez más favorable al gasto que al ahorro (Schmidt, 1990). Gasto para el que algunos contaban con los recursos familiares (el $52 \%$ de los jóvenes entre 15 y 29 años se encontraba en esta situación de dependencia familiar en 1989), otros con los reducidos ingresos que aportaban trabajos precarios que había que complementar con ingresos familiares (jóvenes semi-independientes entre 15 y 29 años que representaban en 1989 el 21\% de la juventud), y el resto con sus propios ingresos, cuando disponían de ocupaciones que les permitían ser independientes (era el caso de los jóvenes entre 25 y 29 años, que suponían el $26,8 \%$ en 1989) (Pais, 1989).

Al mismo tiempo, se producía una creciente valoración del tiempo de ocio entre amigos y pares (ICS, 1987; Ferreira, 1993), aspecto que ya comenzaba a ser valorado a comienzos de los 80 - encuesta FAOJ de 1982 -, cuando más de la mitad de los jóvenes valoraban la amistad como la dimensión que más contribuía a su bienestar.

Todas estas actitudes hacia el ocio y hacia el consumo indicaban que probablemente se estuviese instaurando, también en la juventud portuguesa, una nueva manera de vivir y de concebir el tiempo. No obstante, en el caso de Portugal, no disponemos de encuestas para este periodo que interroguen a los jóvenes directamente sobre esta cuestión. Encuestas que sí existen en el caso de España, y que nos dan a conocer cuál era la temporalidad dominante entre los jóvenes.

\section{Tiempo}

El cambio en la concepción del tiempo de esta generación de jóvenes españoles se advertía ya a comienzos de los años 80 . En efecto, hasta ese momento todavía eran mayoría los que preferían pensar en el futuro antes que "vivir al día". Pero en el 81 eran más los jóvenes (el 60\% de 18 a 24 años) que por el contrario pensaban "que el futuro es tan incierto, que mejor es vivir al día" (Muñoz Carrión, 1994: 213-214), porcentaje que se elevó unos años más tarde - en 1987 - hasta el 70\% (Andrés Orizo, 1985: 54; 1995: 15; De Miguel, 2000: 258).

Todas estas transformaciones, que indicaban una creciente valoración del tiempo de ocio y de consumo, se harán todavía más patentes en la generación siguiente, tal como veremos seguidamente. 


\begin{tabular}{|c|c|c|}
\hline & Valores & Actitudes \\
\hline Educación & $\begin{array}{l}\text { Clases medias y altas: } \\
\text { Valores fuertes: reproducción y movilidad } \\
\text { social. } \\
\text { Clase bajas: } \\
\text { Valores educativos débiles supeditados al } \\
\text { valor trabajo. }\end{array}$ & $\begin{array}{l}\text { Clases medias y altas: } \\
\text { Progreso social e individual. } \\
\text { Clases bajas: } \\
\text { Rápido abandono escolar para integrarse } \\
\text { en el medio laboral. } \\
\text { Orientadas sobre todo a la integración. }\end{array}$ \\
\hline Trabajo & $\begin{array}{l}\text { España: } \\
\text { Menor centralidad del valor trabajo (sobre } \\
\text { todo a partir de mediados de los } 80 \text { ). } \\
\text { Ganan peso los valores instrumentales. } \\
\text { Portugal: } \\
\text { El trabajo sigue siendo relevante como } \\
\text { medio de realización personal y } \\
\text { promoción social. }\end{array}$ & $\begin{array}{l}\text { España: } \\
\text { Sobre todo a partir de mediados de los } \\
80, \text { orientadas a los ingresos, la } \\
\text { sociabilidad y la seguridad. } \\
\text { Entre la integración y la liberación. } \\
\text { Portugal: } \\
\text { Progreso individual y social. } \\
\text { Más favorables a la integración. }\end{array}$ \\
\hline Consumo & $\begin{array}{l}\text { Valores consumistas, hedonistas y de } \\
\text { autoexpresión personal. }\end{array}$ & $\begin{array}{l}\text { Gastar, divertirse y liberarse. } \\
\text { Orientadas a la liberación. }\end{array}$ \\
\hline Tiempo & $\begin{array}{l}\text { España: } \\
\text { A partir de comienzos de los } 80, \text { valores } \\
\text { presentistas. } \\
\text { Portugal: } \\
\text { No hay suficientes datos. }\end{array}$ & Incertidumbre futuro. Vivir al día. \\
\hline
\end{tabular}

Generación 1975-1985

Es la generación de jóvenes más plenamente socializada en los valores del consumo, valores que, como se verá, ejercerán una enorme influencia en la conformación de sus actitudes, incidiendo sustancialmente en la relación que mantendrán estos jóvenes con los otros dos ámbitos, el laboral y el educativo. Es también la juventud con una mentalidad más presentista; la que se desvincula por ello más del pasado, y también la que menos proyecciones hace de futuro.

¿Cómo se manifiestan todas estas actitudes y valores en la relación que mantienen los jóvenes de esta generación con cada uno de los ámbitos objeto de este estudio?

\section{Educación}

En el caso de España las actitudes hacia la educación se producen en un contexto, como el de finales del siglo pasado y comienzos de este, caracterizado por unas elevadas tasas de población escolarizada (González-Anleo, 1999). Situación que, al tiempo que alejaba a los jóvenes del mundo laboral, contribuía a integrarlos más en la esfera del consumo (Martín Serrano y Velarde Hermida, 2001: 250).

En estas circunstancias, los estudios y la formación van cediendo gradualmente en importancia, hasta situarse por detrás del ocio y del tiempo libre, que no deja de ganar en consideración desde 1999 hasta 2010, colocándose en esta última fecha diez puntos por encima de la formación y de los estudios (González-Anleo Sánchez, 2006: 115-116; 2010: 14-15; Funes, 2008: 23). Este declive continuado de la formación en el periodo antes citado se vincula con la enorme pérdida de 
importancia de aspectos tales como los de la promoción y el estatus, la cultura, la utilidad o la obligación moral y social, sólo relevantes para una minoría de jóvenes estudiantes. Mientras que ganan importancia las dimensiones más instrumentales de la educación; a saber, conseguir un título para acceder a un trabajo y relacionarse con los pares (González-Anleo, 1999: 163 y ss.).

No obstante, en este contexto, se observaban importantes diferencias entre los distintos grupos sociales. Así, mientras que para los jóvenes de clase media-alta los estudios todavía se asociaban al éxito profesional y al estatus social, para los de clase media y media-baja, se percibían cada vez más en función del deseo de encontrar un trabajo que proporcionase los ingresos necesarios para el consumo.

En Portugal la juventud de esta generación coincide también, tal como había sucedido en España, con una fuerte expansión educativa, que ya había comenzado a manifestarse en el año 1974, pero que ahora estaba motivada y alentada, al igual que en el país vecino, por las pocas oportunidades que ofrecía el mercado laboral. Así, en 2001 el 26,9\% de los portugueses entre 25 y 29 años había finalizado estudios superiores (INE, 2001), cuando en 1970 esta cifra era sólo del 5\%. La educación deja así de ser vista como una garantía, tal como había ocurrido en la generación precedente, y se convierte en una ocupación y en una necesidad para dar respuesta a las crecientes demandas de un mercado de trabajo cada vez más competitivo y con menos oportunidades laborales (Guerreiro y Abrantes, 2003). En este contexto, la educación superior se percibe con una actitud asociada a la movilidad social, en una generación en la que muy pocos padres habían cursado estudios superiores (Smithson, Lewis y Guerreiro, 1998; Guerreiro y Abrantes, 2003). No obstante, para otros muchos jóvenes universitarios, hijos de las clases más favorecidas, la educación era más bien el camino para la reproducción (en 2004 el 35,7\% de los estudiantes universitarios eran hijos de familias en donde al menos uno de los padres había cursado estudios superiores) (Pappákamail, 2005: 48).

Por lo que respecta a la educación secundaria, en donde casi un $40 \%$ de los jóvenes entre 15 y 17 años ingresaban en 2004 en el mercado de trabajo sin apenas cualificaciones (Guerreiro e Abrantes, 2003), se estaba convirtiendo en un lugar para estar más que para aspirar.

Todo ello se traducía en unos valores educativos más orientados a la sociabilidad que a la meritocracia; sociabilidad con la que se identificaban la inmensa mayoría de los estudiantes. Así, el 97,2\% de los entrevistados en 1998 en una encuesta promovida por el INE manifestaba estar muy o razonablemente satisfechos con la convivencia con sus colegas (Cabral y Pais, 1998).

Trabajo

La cultura del trabajo experimenta también una importante erosión en los jóvenes españoles de esta generación, en relación con sus dificultades de inserción laboral, la precariedad y la carencia de expectativas laborales más o menos sólidas (Conde, 1999: 26 y ss.). Pero también por la prolongación de la edad escolar.

La actitud hacia esta esfera será cada vez más individualista, hedonista e instrumental, tal como se venía ya anunciando, particularmente desde mediados 
de los años 80 (González-Anleo Sánchez, 2006: 116). De este modo ganan peso actitudes tales como ganar dinero para invertir en el ocio y en el consumo (Conde, 1999: 91 y ss.) y "trabajar en lo que me gusta". Mientras que lo pierden otras actitudes vinculadas a "lograr el éxito en el trabajo" (Funes, 2008: 27).

En Portugal, la situación laboral de los jóvenes de esta generación se caracteriza por unos menores niveles de desempleo que en España (en el año 2000 el 14\% de los jóvenes estaba desempleado, lo que suponía $1 / 3$ del desempleo total), pero elevados índices de precariedad laboral (INE, 2001; Smithson, Lewis y Guerreiro, 1998; Capucha, 1998).

Esta situación de inestabilidad y de precariedad laboral, en la que los jóvenes transitan entre empleos diversos, procesos de formación, subempleo o incluso el desempleo, retrasa su incorporación a la vida adulta (Alves, 1998). Así, en 1996 el $80 \%$ de los jóvenes portugueses de entre 20 y 24 años, y el 52\% de los que tenían entre 25 y 29 años, todavía convivía con sus padres (Pappákamail, 2005: 45). En estas circunstancias, los valores laborales de los jóvenes se erosionan gradualmente y se hacen más instrumentales (el $60 \%$ de los jóvenes portugueses valoraban así el trabajo en 1997) (Veira y Muñoz Goy, 2004: 56), en relación con la dificultad que tienen para construir una identidad laboral sólida. Al mismo tiempo, cobra cada vez más importancia el universo del ocio y del consumo. Así, según una investigación cualitativa realizada en 2002 entre un grupo de jóvenes portugueses de entre 16 y 27 años pertenecientes a distintos niveles educativos, muchos de ellos oponían la seriedad, la responsabilidad y las exigencias de la vida laboral al ambiente sociable, autónomo y alegre de los momentos de ocio, subrayando la creciente distancia y separación entre estos dos mundos de vida, y también entre las generaciones que los encarnaban (Pappákamail, 2005: 53-54).

\section{Consumo}

El consumo emerge así como una de las más importantes fuentes de identidad juvenil para los jóvenes de esta generación, tanto portugueses como españoles.

Por lo que se refiere a España, las encuestas de finales del pasado siglo y comienzos del actual mostraban que los jóvenes españoles se definían a sí mismos ante todo como consumidores (CIS, 1997; González-Anleo, 1999: 177; Conde, 1999: 86; González Blasco, 1999: 252; Elzo, 2006: 75; López Ruíz, 2006: 345 y ss.; González-Anleo Sánchez, 2010: 104). Así, valoraban el tiempo dedicado al ocio, y por tanto también al consumo, entre las cosas más importantes de su vida, por delante incluso de los estudios, y después únicamente de la familia, los amigos (vinculados a la sociabilidad consumista), la salud, el trabajo o el dinero; dinero necesario, por otra parte, para invertir en el tiempo dedicado al consumo y el ocio (Andrés Orizo, 1999: 58; Laespada y Salazar, 1999: 360; González-Anleo Sánchez, 2010: 14-15).

Se asiste así a una creciente separación entre los espacios y los tiempos educativos, laborales y de consumo. De este modo, se produce una cesura entre los tiempos y los espacios de ocio festivo, consumista y relacional, y aquellos otros mucho más rutinizados, racionalizados y normativizados pertenecientes al mundo de la educación y del trabajo (Funes, 2008: 139; González-Anleo Sánchez, 2010: 23). 
A medida que los valores del consumo adquieren un mayor protagonismo para los jóvenes en detrimento de los del trabajo y los educativos, las transiciones entre la juventud y la edad adulta se irán también debilitando (Conde, 1999: 224).

En Portugal, los valores del consumo comienzan a cobrar también un especial protagonismo a finales de los años 90 del pasado siglo, en relación con la prolongación de la vida escolar juvenil y también con una integración en el mercado de trabajo cada vez más tardía y precaria (Smithson, Lewis y Guerreiro, 1998; Capucha, 1998). En este contexto, la socialización de la juventud se vincula cada vez más al universo del ocio y del consumo, en busca de una identidad que ya no procura adecuadamente ni el mundo del trabajo ni el educativo. De este modo, las transiciones a la edad adulta se retrasan, y la juventud se dilata cada vez más (Almeida et al., 1998) en relación con los mundos de vida festivos y hedonistas de una sociabilidad celebrativa. Los jóvenes quieren aprovechar así al máximo un tiempo libre de preocupaciones y de responsabilidades en comunión con sus iguales (Nilsen, 1998; Ferreira, 1993). Así lo ponían al menos de manifiesto cuando eran preguntados a finales de la pasada centuria (Pappámikail, 2011: 219-220; 2005: 45). Para ello disponían de unos recursos financieros, que si no les posibilitaban llevar una vida totalmente independiente, al menos les permitían vivir autónomamente en comunión con sus pares (Singly, 2005: 115 y ss.). Esta situación de autonomía con dependencia caracteriza sobre todo a los grupos sociales más favorecidos; en los menos favorecidos la autonomía y la libertad se reducen con la falta de independencia financiera. Quizás por esta razón era en estos grupos en donde los jóvenes se casaban más tempranamente (Guerreiro e Abrantes, 2003).

Esta creciente importancia de la sociabilidad juvenil vinculada al ocio y al consumo, significaba también, tal como sucedía en España, que los tiempos y los espacios juveniles más hedonistas y festivos adquirían un carácter propio, con su particular temporalidad (la noche), sus propios escenarios (los de la calle), sus imágenes y sus símbolos (moda, música, tecnología). Bailar y escuchar música mientras se bebe y se convive con los pares son las principales dimensiones que animan este universo juvenil, mucho más hedonista y celebrativo que contestatario (Pappámikail, 2011: 220 y ss.).

\section{Tiempo}

La orientación temporal de la juventud de esta generación se articula fundamentalmente sobre el eje del presente. Esta era al menos la concepción del tiempo predominante en los jóvenes españoles encuestados entre finales de los años 90 y comienzos de la presente centuria (González Blasco, 1999: 251; Elzo, 2006: 75; González-Anleo Sánchez, 2010: 104; Muñoz Carrión, 2010: 72-73). En efecto, tres de cada cuatro respondieron afirmativamente en 2005 a la pregunta que se venía haciendo regularmente a las distintas generaciones de jóvenes desde los años 60; a saber, "el futuro es tan incierto que lo mejor que se puede hacer es vivir al día" (Muñoz Carrión, 2010: 72-73). 


\begin{tabular}{lll}
\hline & Valores & Actitudes \\
\hline & $\begin{array}{l}\text { Mayor importancia de los valores } \\
\text { instrumentales: } \\
\text { conseguir un título, sociabilidad entre } \\
\text { iguales, sobre todo en las clases bajas } \\
\text { y medias-bajas. } \\
\text { En las medias-altas, sigue valorándose } \\
\text { la educación en relación con el estatus } \\
\text { y la profesión. }\end{array}$ & $\begin{array}{l}\text { Clases bajas y medias-bajas: } \\
\text { Estudiar para conseguir un título. } \\
\text { Interés por relacionarse con los pares. } \\
\text { integración. } \\
\text { Clases medias-altas: }\end{array}$ \\
& $\begin{array}{l}\text { Estudiar para conseguir un buen trabajo. } \\
\text { Trabajo }\end{array}$ & $\begin{array}{l}\text { Reproducir o mejorar la posición social. } \\
\text { A medio camino entre la liberación y la } \\
\text { integración. }\end{array}$ \\
\hline Consumo & $\begin{array}{l}\text { Individualistas, hedonistas e } \\
\text { instrumentales. }\end{array}$ & $\begin{array}{l}\text { Ganar dinero para consumir, trabajar en } \\
\text { lo que a uno le gusta. } \\
\text { Más favorables a la liberación. }\end{array}$ \\
\hline Tiempo & $\begin{array}{l}\text { Consumistas, vinculados al ocio y a la } \\
\text { sociabilidad entre pares. }\end{array}$ & $\begin{array}{l}\text { Consumir, divertirse, relacionarse. } \\
\text { Orientadas a la liberación. }\end{array}$ \\
\hline & Presentistas & $\begin{array}{l}\text { Incertidumbre, vivir el día a día, } \\
\text { posibilistas. }\end{array}$ \\
\hline
\end{tabular}

Esta mentalidad presentista se relaciona con la voluntad y la necesidad de vivir al día; con la preocupación de ganar el dinero suficiente para gastarlo casi inmediatamente (Conde, 1999: 22 y ss., 46).

Esta temporalidad presentista era compartida también por los jóvenes portugueses. Algunos de ellos, entrevistados en 2002 en el curso de una investigación, manifestaron una orientación ante el futuro poco planificada, en la que se apostaba más por una reformulación constante de los planes de vida. Las respuestas más comunes a la pregunta sobre cuáles eran los planes de futuro, fueron: "vivir el presente", "prefiero no pensar a largo plazo" (Pais, 2003b, cit. en Pappákamail, 2005: 52). El futuro deja de ser así algo planificado para convertirse en una especie de presente ficticio desde el que "la incertidumbre y la imprevisibilidad del presente es desterrada", en virtud de sus múltiples posibilidades (Pais, 2003b: 123 y ss.). Quizás por esa razón, porque la juventud se sumerge en un presente abierto e intenso en posibilidades de gozarlo y de recrearlo, el 90\% de los jóvenes portugueses de entre 15 y 24 años, encuestados en 1995 (encuesta realizada por el ICS - Instituto de Ciências Sociais), consideraba que la vida era una agradable aventura, y no una preocupación tras otra (así lo afirmaba el $70 \%$ ). Y por esa misma razón, acaso también, una mayoría de ellos (el 87\%) manifestase tener confianza en el futuro, a pesar de vivir volcados en el presente. Un presente abierto en el que los jóvenes tratan de vivir intensamente buscando la autonomía y la liberación antes que la integración. 


\section{Conclusiones}

Hemos planteado al comienzo de este trabajo el análisis de tres generaciones de jóvenes españoles y portugueses en relación con sus valores y actitudes hacia el trabajo, la educación y el consumo, y también con respecto a sus representaciones del tiempo, en el contexto del proceso de transición de una sociedad rural-preindustrial a otra urbana-industrial, y de esta a la postindustrial. Los resultados confirman en líneas generales nuestros presupuestos de partida, aunque con importantes matices diferenciales entre los dos países ibéricos.

La primera generación - la de los nacidos entre 1935/1945 - es la que muestra una mayor valoración de la educación y del trabajo, valoración que se manifiesta en su orientación hacia el logro y el estatus como camino para superar o para reproducir sus condiciones de clase. Permanece aún vinculada a los valores tradicionales, sobre todo en lo que respecta al mundo de la familia. Su valoración del ocio y del tiempo libre, y por tanto también del consumo, es todavía muy escasa, y está supeditada al tiempo dominante que es el productivo. Se trata, en suma, de una generación materialista y futurista, con una fuerte conciencia institucional, manifestada en el respeto por los valores vinculados a la autoridad y a la jerarquía, y por una mayor orientación a la integración que a la liberación.

La segunda generación - la del periodo 1955-1965 - integra por primera vez las tres esferas, siendo la del consumo la que comienza a ejercer una mayor influencia sobre las otras dos, fundamentalmente en los jóvenes nacidos en los años 60 . Se sitúa por ello en el proceso de transición entre los valores materialistas y los postmaterialistas (Inglehart, 1990). De todos modos, hay ciertos indicios de que este proceso comienza primero en España, a principios de los años 80, y más tarde en Portugal, a partir de mediados de los 90. Hasta ese momento los valores de la educación y del trabajo mantendrían un significado vinculado todavía al estatus y al logro, interpretado de distinto modo en función de las diferentes clases sociales. Pero, a partir de esa fecha, ambos valores comenzarán a adquirir un carácter más instrumental, por su incapacidad para atender a sus objetivos proclamados, merced a la precariedad y a la falta de expectativas laborales, en un contexto, además, de prolongación de la edad escolar. En estas circunstancias empiezan a ser mediados por los valores del consumo. Simultáneamente, se observa un cambio en las concepciones del tiempo, imponiéndose gradualmente los valores del presente. Un presente vinculado a las actitudes hedonistas de una juventud que quiere vivir su vida cada vez más intensamente.

Toda esta situación prefigura los valores dominantes en la siguiente generación, la del periodo 1975-1985. En ella se imponen definitivamente los valores del consumo sobre los del trabajo y la educación. En efecto, debido a la débil integración que procuran las esferas de la educación y del trabajo, cada vez menos vinculadas con los valores del logro y del estatus, y al auge del universo del consumo, con el que se identifican mayoritariamente los jóvenes, ambas esferas serán penetradas por la del consumo adquiriendo una dimensión fundamentalmente instrumental y expresiva. Dimensión que se relaciona sobre todo con los ingresos y la autorrealización personal, en el caso del trabajo; y con las redes de amistad entre pares que comparten un mismo estilo de vida, en el ámbito educativo. 
Como consecuencia de todo este proceso, se retrasan las transiciones al mundo adulto, y se produce una cesura entre los tres ámbitos aquí analizados. Cesura que se escenifica en la separación, que no en la confrontación, entre el tiempo hedonista y expresivo del consumo, y el tiempo más rutinizado, normativizado y racionalizado del mundo productivo y educativo, cada vez más vacío de sentido. Esta creciente escisión entre la esfera institucional y la relacional; entre la que apela más a la incorporación y la que lo hace sobre todo a la liberación, se pone de manifiesto en el deseo de la juventud de vivir al margen de las ataduras institucionales, en comunión inmediata con sus iguales. Y se materializa en la manera que tienen los jóvenes de habitar los espacios y de vivir el tiempo. Un tiempo que tratan de aprovechar intensamente sin preocuparse demasiado por el mañana.

\section{Bibliografía}

Almeida, A. N. de, et al. (1998), "Relações familiares: mudança e diversidade", en J. M. Leite Viegas y A. Firmino da Costa (coords.), Portugal, Que Modernidade? Oeiras, Celta Editora, pp. 45-78.

Alonso, L. E., y F. Conde (1994), La Historia del Consumo en España.Una Aproximación a Sus Orígenes y Primer Desarrollo, Madrid, Debate.

Alves, N. (1998), “Escola e trabalho: atitudes, projectos e trajectórias”, en M. Villaverde Cabral y J. Machado Pais (orgs.), Jovens Portugueses de Hoje, Oeiras, Celta Editora, pp. 53-133.

Andrade, M. (1989), A Juventude Portuguesa. Situaçoões, Problemas e Aspiraçoões. O Trabalho, o Emprego, a Profissão, vol III, Lisboa, ICS.

Andrade, S. P. C., S. R. Tolfo, y E. H. L. Dellagnelo (2012), “Sentidos do trabalho e racionalidades instrumental e substantiva: interfaces entre a administração e a psicologia", Revista de Administração Contemporânea, 16 (2), pp. 200-216.

Andrés Orizo, F. (1983), España, entre la Apatía y el Cambio Social, Madrid, Mapfre.

Andrés Orizo, F. (1985), "Estructuras básicas de la población juvenil", en F. Andrés Orizo (coord.), Juventud Española 1984, Madrid, Fundación SM, pp. 29-57.

Andrés Orizo, F. (1989), “Fuerza de personalidad y liderazgo", en P. González Blasco, (dir.), Jóvenes Españoles 89, Madrid, Fundación SM, pp. 145-205.

Andrés Orizo, F. (1995), Dinámica Intergeneracional del Sistema de Valores Españoles, Madrid, CIS.

Andrés Orizo, F. (1999), “Jóvenes: sociedad e instituciones”, en J. Elzo (coord.), Jóvenes Españoles 99, Madrid, Fundación SM, pp. 53-120.

Andrés Orizo, F. (2001), Sistema de Valores en la España de los 90, Madrid, CIS.

Bauman, Z. (2007), Vida de Consumo, Madrid, FCE.

Bauman, Z. (2009), Mundo de Consumo, Barcelona, Paidós.

Becci, E., y D. Julia (1998), Histoire de l'Enfance en Occident, de l'Antiquité au XVII Siècle, París, Editions du Seuil.

Beck, U. (2006), La Sociedad del Riesgo. Hacia Una Nueva Modernidad, Barcelona, Paidós. Bell, D. (1977), Las Contradicciones Culturales del Capitalismo, Madrid, Alianza Editorial. 
Beltrán Villalba, M. (coord.) (1984), Informe Sociológico sobre la Juventud Española, 1960/82, Madrid, Fundación SM.

Cabral, M. V., y J. M. Pais (coords.) (1998), Jovens Portugueses de Hoje, Oeiras, Celta Editora.

Cabral, M. V., J. Vala, y J. Freire (2000), Atitudes Sociais dos Portugueses, Trabalho e Cidadania, Lisboa, ICS.

Capucha, L. (1998), "Pobreza, exclusão social e marginalidades", en J. M. L. Viegas y A. Firmino da Costa (orgs.), Portugal, Que Modernidade?, Oeiras, Celta Editora, pp. 209-242.

CIS (1997), Juventud y Entorno Familiar, Madrid, Injuve.

Comas Arnau, D. (2000), “Agobio y normalidad: una mirada crítica sobre el sector 'ocio juvenil' en la España actual", Estudios de Juventud, 50, pp. 9-22.

Comas Arnau, D. (coord.) (2003), Jóvenes y Estilos de Vida, Madrid, Injuve.

Comas Arnau, D. (2015), “Ocio y tiempo libre: identidades y alternativas”, Revista de Estudios de Juventud, 100, pp. 9-22.

Conde, F. (1999), Los Hijos de la Desregulación. Jóvenes, Usos y Abusos en los Consumos de Drogas, Madrid, CREFAT.

Cruz, B. D., J. M. Seruya, L. B. Reis, y L. Schmidt (1984), “A condição social da juventude portuguesa", Análise social, XX (81-82), pp. 285-308.

De Lora, C. (1965), Juventud Española Actual, Madrid, Ediciones y Publicaciones Españolas.

De Miguel, A. (1992), La Sociedad Española, 1992-1993, Madrid, Alianza Editorial.

De Miguel, A. (2000), Dos Generaciones de Jóvenes, 1960-1998, Madrid, Ministerio de Trabajo y Asuntos Sociales.

Duque, E. (2007), Os jovens e a Religião na Sociedade Actual. Comportamentos, Crenças, Atitudes e Valores no Distrito de Braga, Braga, Instituto Português da Juventude.

Elzo, J. (coord.) (1994), Jóvenes Españoles 94, Madrid, Fundación SM.

Elzo, J. (1999), “Reflexiones finales”, en J. Elzo (coord.), Jóvenes Españoles 99, Madrid, Fundación SM, pp. 401-403.

Elzo, J. (2006), “Valores e identidades de los jóvenes”, en P. González Blasco (dir.), Jóvenes Españoles 2005, Madrid, Fundación SM, pp. 3-110.

Eurostat (2014), Estadísticas de Empleo, obtenido el 9 de septiembre de 2014 en: http://epp.eurostat.ec.europa.eu/statistics_explained/index.php/Employment_stati stics/pt

Ferreira, P. A. (1993), Valores dos Jovens Portugueses nos Anos 80, Lisboa, Instituto de Ciências Sociais/Instituto da Juventude.

Funes, M. ${ }^{-}$J. (2008), Cultura, Política y Sociedad, vol. 4 de: Injuve, Informe Juventud en España 2008, Madrid, Injuve.

Gauchet, M. (2002), La Démocratie contre Elle-Même, París, Gallimard.

González-Anleo, J. (1999), “Familia y escuela en la socialización de los jóvenes españoles”, en J. Elzo (coord.), Jóvenes Españoles 99, Madrid, Fundación SM, pp. 121-182.

González-Anleo Sánchez, J. M. (2006), “Relaciones e integración”, en P. González Blasco, (dir.), Jóvenes Españoles 2005, Madrid, Fundación SM, pp. 111-184.

González-Anleo Sánchez, J. M. (2014), Consumidores Consumidos. Juventud y Cultura Consumista, Madrid, Khaf.

González-Anleo, J., y P. González Blasco (coords.) (2010), Jóvenes Españoles 2010, Madrid, Fundación SM. 
González Blasco, P. (1989), Jóvenes Españoles 89, Madrid, Fundación SM.

González Blasco, P. (1994), “Los jóvenes y su identidad”, en J. Elzo (dir.), Jóvenes Españoles 94, Madrid, Fundación SM, pp. 25-88.

González Blasco, P. (1999), "Relaciones sociales y espacios vivenciales”, en J. Elzo (coord.), Jóvenes Españoles 99, Madrid, Fundación SM, pp. 183-262.

González Blasco, P. (dir.) (2006), Jóvenes Españoles 2005, Madrid, Fundación SM.

Guerreiro, M. D., y P. Abrantes (2003), Transições Incertas. Os Jovens perante o Trabalho e a Família, Lisboa, CIES.

ICS - Instituto de Ciências Sociais (1987), A Juventude Portuguesa. Situações, Problemas e Aspirações, Lisboa, ICS.

Inglehart, R. (1990), Cambio Cultural en las Sociedades Industriales Avanzadas, Madrid, CIS.

INE - Instituto Nacional de Estatística (1960), X Recenseamento Geral da População, 1960, tomo III, vol. $2^{\circ}$, Lisboa, INE.

INE - Instituto Nacional de Estatística (2001), Censos 2001. Resultados Definitivos. XIV Recenseamento Geral da População, Lisboa, INE.

Laespada, M. T., y L. Salazar (1999), “Las actividades no formalizadas de los jóvenes”, en J. Elzo (coord.), Jóvenes Españoles 99, Madrid, Fundación SM, pp. 355-400.

Leccardi, C., y C. Feixa (2011), “El concepto de generación en las teorías sobre la juventud", Última Década, 34, Junio, pp. 11-32.

Lévi G., y J. C. Schmitt (orgs.) (1996), Histoire des Jeunes en Occident (2 vols.), París, Editions du Seuil.

López Ruíz, J. A. (2006), “Ocio y tiempo libre”, en P. González Blasco (dir.), Jóvenes Españoles 2005, Madrid, Fundación SM, pp. 345-402.

Mannheim, K. (1990), Le Problème des Génerations, París, Natham.

Margulis, M., y M. Urresti (1996), "La juventud es más que una palabra”, en M. Margulis, La Juventud Es Más que Una Palabra. Ensayos sobre Cultura y Juventud, Buenos Aires, Biblos, pp. 13-30.

Martín Criado, E. (1998), Producir la Juventud. Crítica de la Sociología de la Juventud, Madrid, Istmo.

Martín Escudero, M. (1994), "Estudio y trabajo", en M. Martín Serrano (dir.), Historia de los Cambios de Mentalidades de los Jóvenes entre 1960-1990, Madrid, Injuve, pp. 129-169.

Martín Serrano, M. (dir.) (1994), Historia de los Cambios de Mentalidades de los Jóvenes entre 1960-1990, Madrid, Injuve.

Martín Serrano, M., y O. Velarde Hermida (coords.) (2001), Informe Juventud en España 2000, Madrid, Injuve.

Mauritti, R. (2002), “Padrões de vida dos estudantes universitários nos procesos de transição para a vida adulta", Sociologia, Problemas e Práticas, 39, pp. 85-116.

Mead, M. (1971), Cultura y Compromiso. Estudio sobre la Ruptura Generacional, Buenos Aires, Granica.

Moya, C. (1984), Señas de Leviatán. Estado Nacional y Sociedad Industrial. España 1936-1980, Madrid, Alianza Editorial.

Muñoz Carrión, A. (1994), “Aspiraciones y objetivos existenciales”, en M. Serrano (dir.), Historia de los Cambios de Mentalidades de los Jóvenes entre 1960-1990, Madrid, Injuve, pp. 207-220. 
Muñoz Carrión, A. (2010), “El tiempo subjetivo de los jóvenes: hacia un régimen de la inmediatez", en J. C. Mingote y M. Requena (orgs.), El Malestar de los Jóvenes. Contextos, Raíces y Experiencias, Madrid, Ediciones Díaz de Santos, pp. 67-98.

Nilsen, A. (1998), “Jovens para sempre? Uma perspectiva da individualização centrada nos trajectos de vida", Sociologia, Problemas e Práticas, 27, pp. 59-78.

Nunes, A. S. (1968), "População universitária portuguesa: análise preliminar", Análise Social, VI (22-24), pp. 295-385.

OECD, National Accounts Statistics, disponible en: http://www.oecd-ilibrary.org/economics/data/oecd-national-accounts-statistics_nadata-en (última consulta en junio de 2017).

Ortí, A. (1982), Unidad y Diversidad de la Mentalidad y Actitudes Ideológicas Juveniles en la Postransición Democrática, Madrid (inédito).

Pais, J. M. (1989), Juventude Portuguesa. Situações, Problemas, Aspirações - A Convivialidade e a Relação com os Outros. Lisboa, Instituto da Juventude e Instituto de Ciências Sociais da Universidade de Lisboa.

Pais, J. M. (1996), “Levantamento bibliográfico de pesquisas sobre a juventude portuguesa - tradições e mudanças (1985-1995), Sociologia, Problemas e Práticas, 21, pp. 197-221.

Pais, J. M. (org.) (1998), Gerações e Valores na Sociedade Portuguesa Contemporânea, Lisboa, Instituto de Ciências Sociais da Universidade de Lisboa.

Pais, J. M. (2003a), Culturas Juvenis, Lisboa, Imprensa Nacional Casa da Moeda.

Pais, J. M. (2003b), "The multiple faces of the future in the labyrinth of life", Journal of Youth Studies, 6 (2), pp. 115-126.

Pais, J. M. (2005a), Ganchos, Tachos e Biscates. Jovens, Trabalho e Futuro, Porto, Âmbar.

Pais, J. M. (2005b), “Alguns dados para uma reflexão sobre os jovens portugueses”, en Encontro de Jovens da Serra do Caldeirão, São Brás de Alportel, s.d. (documento policopiado).

Pais, J. M. (2009), “A juventude como fase de vida: dos ritos de passagem aos ritos de impasse", Saúde e Sociedade, 18 (3), pp. 371-381.

Pais, J. M., y M. V. Cabral (orgs.) (1998), Jovens Portugueses de Hoje, Oeiras, Celta Editora.

Pallarés Gómez, C., y J. Feixa Pampols (2015), “Espacios e itinerarios para el ocio juvenil nocturno", Revista de Estudios de Juventud, 100, pp. 23-41.

Pappámikail, L. (2005), “Sentidos de la edad adulta: juventud y cambio social en el Portugal contemporáneo", Revista de Estudios de Juventud, 71, pp. 43-55.

Pappámikail, L. (2011), "Juventude entre a fase da vida e tempo de viver", en A. Nunes de Almeida (coord.), Historia da Vida Privada, vol. 4, Lisboa, Temas \& Debates, pp. 208-241.

Pordata (2014), "Portugal, emprego e mercado de trabalho", disponible en: http://www.pordata.pt/Tema/Portugal/Emprego+e+Mercado+de+Trabalho-3 (última consulta en junio de 2017).

Rocha, E. (1977), “Portugal, anos 60: crescimento económico acelerado e papel das relações com as colónias", Análise Social, XIII (51), pp. 593-617.

Savage, J. (2007), Teenage. The Creation of Routh Culture, Londres, Randon House.

Schmidt, L. (1989), A Juventude Portuguesa. Situações, Problemas, Aspirações, vol. 7: Dinheiro e Bens Materiais, Lisboa, Instituto de Ciências Sociais da Universidade de Lisboa. 
Schmidt, L. (1990), “Jovens: família, dinheiro, autonomia”, Análise social, XXV (108-109), pp. 645-673.

Silva, P., y M. T. Pereira (2012), "As políticas de proteção no desemprego em Portugal”, Sociologia, Problemas e Práticas, 70, pp. 133-150.

Singly, F. (2005), "Las formas de terminar y no terminar la juventud”, Revista de Estudios de Juventud, 71, pp. 111-121.

Smithson, J. S. Lewis, y M. D. Guerreiro (1998), “Percepções dos jovens sobre a insegurança no emprego e suas implicações no trabalho e na vida familiar", Sociologia, Problemas e Práticas, 27, pp. 97-113.

Veira, J. L., y C. Muñoz Goy (2004), “Valores y actitudes del trabajo en Europa Occidental", RES, 4, pp. 51-66.

Velarde, O. (1994), "Los valores en torno a la familia y a la sexualidad", en M. Serrano (dir.), Historia de los Cambios de Mentalidades de los Jóvenes entre 1960-1990, Madrid, Injuve, pp. 99-126.

Willis, P. (1988), Aprendiendo a Trabajar, Madrid, Akal.

José Francisco Durán Vázquez. Licenciado y doctor en Sociología, licenciado en Geografía e Historia y en Ciencias Políticas. Profesor de Sociología en la Universidad de Vigo, Vigo, España. E-mail: joseduran@uvigo.es

Eduardo Duque. Doctor en Sociología. Profesor de Sociología en la Universidade Católica de Braga y membro de CECS, Universidade do Minho, Braga, Portugal. E-mail: eduardoduque@braga.ucp.pt

Receção: 23 de junho de 2016 Aprovação: 12 de julho de 2017 